\title{
Time series of coccolithophore activity in the Barents Sea, from twenty years of satellite imagery
}

\author{
T. J. Smyth \\ Plymouth Marine Laboratory, Plymouth, UK
}

T. Tyrrell

School of Ocean and Earth Science, Southampton Oceanography Centre, University of Southampton, Southampton, UK

\section{B. Tarrant}

Department of Geography, University College London, London, UK

Received 16 February 2004; accepted 29 April 2004; published 2 June 2004.

[1] Blooms of the coccolithophorid Emiliana huxleyi may be sensitive to climate change. A comparison of global Coastal Zone Color Scanner (CZCS, 1978-1986) and Seaviewing Wide Field-of-view Sensor (SeaWiFS, 1997present) imagery appears to show them advancing into some sub-Arctic seas. To determine when coccolithophore blooms appeared in the Barents Sea this paper makes use of Advanced Very High Resolution Radiometer (AVHRR) visible channel data which bridges the gap between the CZCS and SeaWiFS missions (1981-present). Analysis of over 3700 AVHRR images has shown coccolithophore blooms to be unambiguously present between 1989-1992 but probably absent in other pre-SeaWiFS years. This paper shows a correlation between positive temperature - negative salinity anomalies in the Barents Sea and bloom occurrence. If global warming continues to trigger increased warmth and freshwater runoff in the region then there may be an increased frequency of coccolithophore blooms within the Barents Sea. INDEX TERMS: 1640 Global Change: Remote sensing; 4275 Oceanography: General: Remote sensing and electromagnetic processes (0689); 4847 Oceanography: Biological and Chemical: Optics; 4552 Oceanography: Physical: Ocean optics; 4207 Oceanography: General: Arctic and Antarctic oceanography. Citation: Smyth, T. J., T. Tyrrell, and B. Tarrant (2004), Time series of coccolithophore activity in the Barents Sea, from twenty years of satellite imagery, Geophys. Res. Lett., 31, L11302, doi:10.1029/2004GL019735.

\section{Introduction}

[2] Coccolithophores are phytoplankton that synthesise external calcium carbonate platelets (coccoliths or liths): during the latter stages of a bloom these coccoliths are shed in large numbers giving the water a turquoise-white appearance which is easily detectable both at the surface and from space. The unique satellite visibility of coccolithophore blooms provides data that are not available for any other phytoplankton species allowing testing of hypotheses about temporal changes in their distribution. A comparison of global Coastal Zone Color Scanner (CZCS, 1978-1986) and Sea-viewing Wide Field-of-view Sensor (SeaWiFS, 1997-present) maps show significant differences in the

Copyright 2004 by the American Geophysical Union. 0094-8276/04/2004GL019735\$05.00 distribution of coccolithophore blooms [Brown and Yoder, 1994; Iglesias-Rodriguez et al., 2002]. Coccolithophores appear to be advancing into some sub-Arctic seas, for example the Bering Sea [Merico et al., 2003], while perhaps becoming more scarce in some parts of their equatorward distribution, such as the Gulf of Maine. Coccolithophores may therefore be sensitive to, and important indicators of, climate change. Coccolithophores are also important contributors to the inorganic carbon pump in the oceans, and their future fate in response to global change is therefore of concern.

[3] The Barents Sea is an extreme environment on account of its high latitude, large seasonal and annual changes in ocean climate, and its position near the Arctic Ocean. The sea is bounded by Atlantic water (sea-surface temperature (SST) $\geq 2{ }^{\circ} \mathrm{C}$; salinity $35.0 \mathrm{psu}$ ) in the south and west, and by Arctic or 'mixed' water $\left(\mathrm{SST}<0^{\circ} \mathrm{C}\right.$; salinity between 34.3 and $34.8 \mathrm{psu}$ ) to the north and east. Ice covers between one- and two-thirds of the Barents Sea in winter and shows considerable annual and inter-annual variability [Kögeler and Rey, 1999]. The climatic variations within the Barents Sea are strongly influenced by the temperature of the inflowing Atlantic water. These climatic conditions coupled with the extent of the ice cover have a pronounced effect on the biology and help explain interannual variations in spring phytoplankton bloom and coccolithophore succession [Kögeler and Rey, 1999; Anseleme, 1998].

[4] In this paper Advanced Very-High Resolution Radiometer (AVHRR, 1982-present) visible channel data are examined to determine when coccolithophores first appeared in the Barents Sea. This sensor, carried on board the NOAA series of satellites, bridges the 11 year gap between SeaWiFS and CZCS. However, due to lower inherent reflectances in AVHRR channel $1(0.580-$ $0.680 \mu \mathrm{m})$ and lower detector gain, it is only $11 \%$ as sensitive to variation in coccolithophore reflectance as CZCS channel $3(0.540-0.560 \mu \mathrm{m})$ [Groom and Holligan, 1987] and $3 \%$ as sensitive as SeaWiFS channel $5(0.545-$ $0.565 \mu \mathrm{m})$ (S. Groom, personal communication).

\section{Method}

[5] Approximately 3700 scenes of AVHRR data at $4.4 \mathrm{~km}$ resolution covering the Barents Sea, for the months of June to 
September inclusive, from 1982 to 2002 were obtained from the NOAA Satellite Active Archive and processed using software developed at the Plymouth Marine Laboratory.

\subsection{Theory}

[6] The raw visible and infra-red channels 1 and 2 were converted into a calibrated radiance using:

$$
L=A \exp (B d)(C(10)-C(0))
$$

where $\mathrm{L}$ is the radiance in $\mathrm{Wm}^{-2} \mu \mathrm{m}^{-1} \mathrm{sr}^{-1}, \mathrm{~d}$ the number of days since launch, $\mathrm{C}(10)$ the measured counts on the 10-bit scale and $\mathrm{A}, \mathrm{B}$ and $\mathrm{C}(0)$ are parameters which describe the degradation of the sensors [Rao and Chen, $1995,1996]$. The sensor degradation parameters are required if a comparison is to be made between the reflectivities measured by the different AVHRR sensors; these are only known for NOAA-7, 9, 11 and 14 and only imagery from these sensors was used in this paper. (The NOAA-16 data obtained for 2003 could therefore only be used in a qualitative sense.) The raw visible and near infra-red channels 1 and 2 were then converted into reflectance using the calibrated radiance, the variable Earth-Sun separation, the extra-terrestrial solar irradiance [Neckel and Labs, 1984] and the solar zenith angle. The signal detected by the satellite is composed of a small water and a larger atmospheric component. The atmospheric component can be split up into the atmospheric diffuse and ozone transmittance, Rayleigh and aerosol scattering terms. The first three terms can be calculated from surface pressure, ozone concentration and sun-pixel-satellite geometry. Climatological values of surface pressure and ozone concentration were used in this paper. The aerosol scattering is more problematic as aerosol optical properties are generally unknown. However, assuming the same aerosol reflectance in AVHRR channels 1 and $2(0.725-1.1 \mu \mathrm{m})$ [Stumpf and Pennock, 1989] and that the remote sensing reflectance (Rrs) is zero in channel 2, the effect of aerosols can be removed using the equation:

$$
R r s=\frac{R 1-R 2}{\exp ((-0.057 / 2) \times p l)}
$$

where R1 and R2 are the Rayleigh corrected AVHRR channel 1 and 2 reflectances respectively. The factor of 0.057 is the calculated value of the Rayleigh optical depth in channel 1 for a path length (pl) of unity and a standard atmosphere; pl itself being a function of the satellite and solar zenith angle.

[7] The above procedure is a slight modification of the method of [Groom and Holligan, 1987] which has been successfully applied in the past at high latitudes in the North Atlantic [Holligan et al., 1993] and in polar waters (about $70^{\circ} \mathrm{N}$ ) [Trees et al., 1992] to detect coccolithophores.

\subsection{Potential Problems}

[8] There are several potential problems that this study had to consider. Firstly the Barents Sea region is often covered by cloud (typically $80 \%$ cloud cover during the summer months [Rossow and Schiffer, 1999]). As a consequence this approach may not produce firm evidence for the absence (null result) of coccolithophore blooms for a

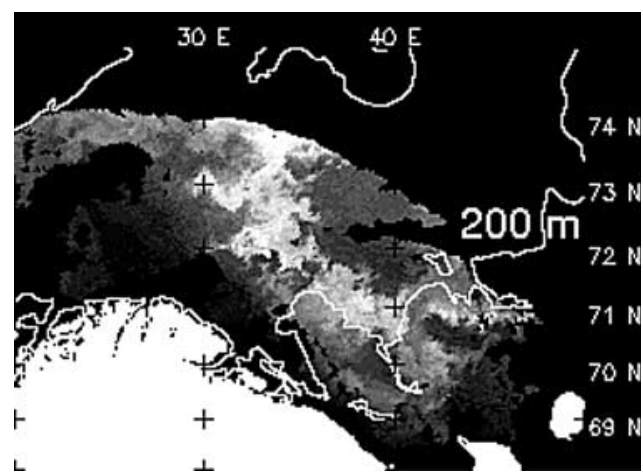

Figure 1. AVHRR (NOAA-11) reflectance product for 5 August 1989 10:11 UTC showing an extensive patch of bright waters due to coccolithophores. The $200 \mathrm{~m}$ isobath is marked in white.

particular year or season. However, the duration of such blooms' visibility (typically several months in the Bering Sea [Merico et al., 2003] and several weeks in the N. Atlantic [Holligan et al., 1993]) means that only a few clear scenes are required over a whole season to determine whether or not a bloom has occurred. Secondly, algorithms to detect the presence of coccolithophores can be erroneously triggered if the water contains sediments due to glacial or riverine inputs, or resuspended diatom frustules [Broerse et al., 2003]. These inputs tend to be close to the coast or near the outfalls of glaciers or in winter and are unable to account for such large areas $\left(\sim 10^{3} \mathrm{~km}^{2}\right)$ of offshore bright waters in summer.

\section{Results}

[9] Figure 1 shows one of the earliest images in the AVHRR time series to unambiguously show the presence of a coccolithophore bloom. It shows the bloom stretching along the $200 \mathrm{~m}$ isobath between $45^{\circ}$ and $35^{\circ} \mathrm{E}$ and then northward between $72^{\circ}$ and $74^{\circ} \mathrm{N}$. A wider spatial coverage to the north is possibly obscured by cloud. Eddy structure is clearly visible at the edges of the bloom. Figure 2 shows the location of possible coccolithophore blooms between 1987 and 2002: this being generated from monthly composite AVHRR reflectance imagery. The monthly images were then checked for any residual atmospheric effects and a reflectance threshold subjectively set based on visual inspection of any bloom; these were then amalgamated into a seasonal picture giving a single (grey) value to where the threshold was exceeded. This figure confirms that there were blooms within the Barents Sea between the CZCS and SeaWiFS missions and that in years where blooms were detected they generally occurred in August. To confirm that the radiometric sensitivity of AVHRR is sufficient to detect typical coccolithophore blooms Figure 3 shows a qualitative comparison between an AVHRR (NOAA-16) reflectance and contemporary Moderate Imaging Spectroradiometer (MODIS) true colour composite on 19 July 2003. Both images show the high reflectances associated with coccolithophores between the northern Norwegian coast and $74^{\circ} \mathrm{N}$. However, the MODIS imagery shows greater longitudinal extent of the bloom because of the sensor's greater radiometric sensitivity. In situ sampling in the region one month 


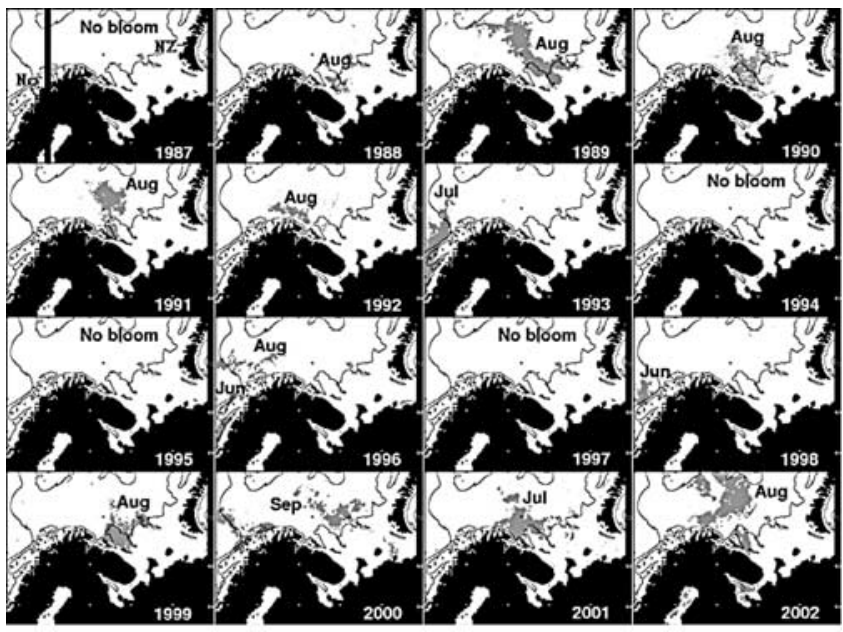

Figure 2. Location and timing of coccolithophore blooms in a region between $62-76^{\circ} \mathrm{N} ; 10-60^{\circ} \mathrm{E}$ determined using composite reflectance imagery between 1987 and 2002. The maximum extent of the blooms are shaded in grey, determined using reflectance thresholding. The $20^{\circ} \mathrm{E}$ meridian is marked in the 1987 panel together with the location of Norway (No) and Novaya Zemlya (NZ).

later at $73^{\circ} 36^{\prime} \mathrm{N}, 26^{\circ} 48^{\prime} \mathrm{E}$ confirmed the presence of high concentrations of $E$. huxleyi coccoliths as the cause of the bright water.

[10] Using the $20^{\circ} \mathrm{E}$ meridian as an arbitrary delimiter of the Barents Sea western boundary then coccolithophore blooms occurred in the AVHRR time series between 1988-1992 and 1999-2002. Blooms also occurred in 1985, 1993, 1996 and 1998 but these were mainly constrained to the western side of the $20^{\circ} \mathrm{E}$ meridian and were of an Atlantic origin.

\section{Discussion and Conclusions}

[11] Bright waters seen in SeaWiFS imagery of the Barents Sea every summer between 1998 and 2003 are likely to be of the coccolithophore species Emiliana huxleyi: this was confirmed by in situ sampling in 2003. Our analysis of archived AVHRR reflectance imagery reveals that the incidence of these blooms within the Barents Sea is not a new phenomenon, having occurred previously (unambiguously) between 1989 and 1992 .

[12] The only year where AVHRR failed to unambiguously flag a bloom that was detected by SeaWiFS was 1998 . A possible reason for this is that the 1998 bloom, situated in roughly the same location as the 2003 occurrence, was

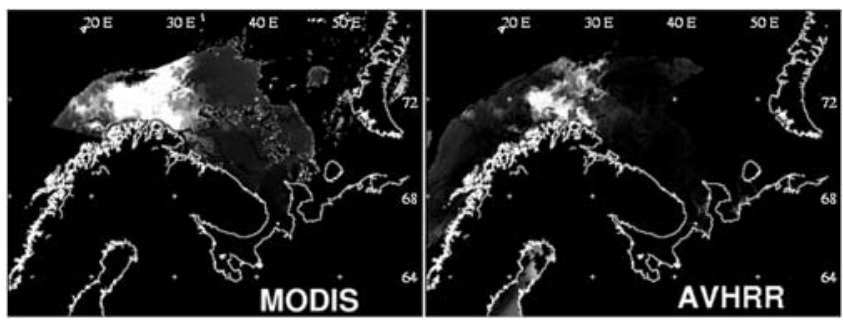

Figure 3. MODIS true colour composite at 16:10 UTC together with the AVHRR reflectance product for 09:23 UTC on 19 July 2003.
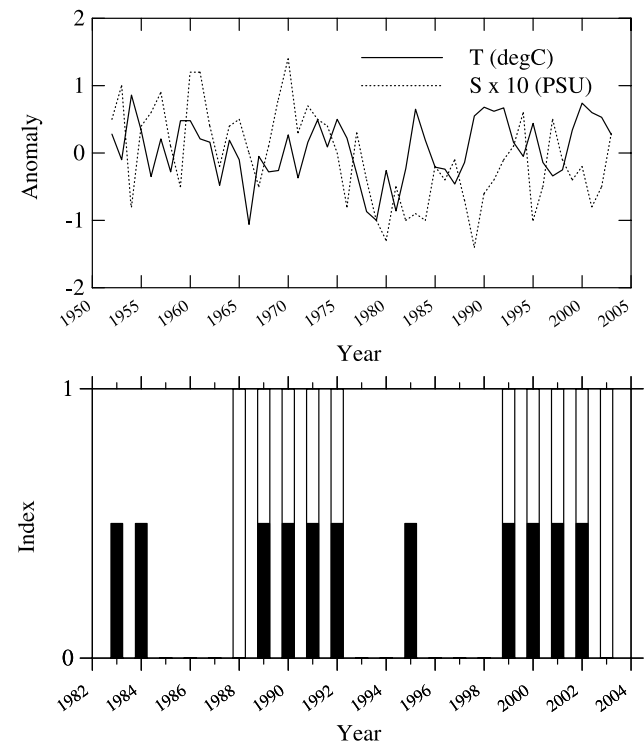

Figure 4. Top panel show the annual average temperature and salinity anomalies for the Kola transect $(0-200 \mathrm{~m}$; between $70^{\circ} 30^{\prime}-72^{\circ} 30^{\prime} \mathrm{N}$ along $33^{\circ} 30^{\prime} \mathrm{E}$ ) compared with the 1951-1990 mean. The lower panel shows the AVHRR detected bloom occurrence as unfilled bars and the positive temperature - negative salinity anomaly occurrence as filled bars.

rather weak and gave a less intense brightening than is normal for these blooms.

[13] Figure 4 shows the temperature (T) and salinity (S) anomalies for stations 3-7 of the Kola survey transect (between $70^{\circ} 30^{\prime}-72^{\circ} 30^{\prime} \mathrm{N}$ along $33^{\circ} 30^{\prime} \mathrm{E}$ for the top $200 \mathrm{~m}$ [Bochkov, 1982]) together with an index of bloom occurrence and TS pairings. The TS pairing flag is set where there is a positive temperature coincidental with a negative salinity anomaly (i.e., water warmer and fresher than usual). If this transect is considered to be typical of the physical oceanography within the southern-central Barents Sea then it appears that there is a good correlation between the TS pairing and coccolithophore occurrence; the probability of this happening by chance is 0.03 . Within the 52 year TS record fourteen years have this particular pairing, eleven of these occurring since 1983. Eight of the eleven years had blooms detected east of $20^{\circ} \mathrm{E}$ these being between $1989-$ 1992 and 1999-2002. The years without blooms but with the TS pairing (1983, 1984 and 1995) all had strong $(<-0.09$ psu $)$ salinity anomalies and two of these $(1983$ and 1995) are markedly warm $\left(>0.44^{\circ} \mathrm{C}\right)$. This suggests that in these years another factor, such as meteorological forcing, was important for the growth and development of E. huxleyi blooms in the Barents Sea. The small bloom detected in 1988 could possibly be caused by highly reflective sediments from glacial runoff or diatom frustules [Broerse et al., 2003]. However, the 2003 bloom, detected using MODIS and AVHRR and in situ sampling is a definite coccolithophore bloom and occurred when the surrounding waters were warmer but more saline than normal.

[14] According to the null hypothesis just because the CZCS imagery did not give evidence for the presence of coccolithophore blooms this did not mean that they did not occur. A further investigation of the availability of CZCS 
imagery in the Barents Sea for a region between $72-76^{\circ} \mathrm{N}$ and $30-50^{\circ} \mathrm{E}$ shows that only 87 scenes were available over the entire time period between 1979 and 1986. This compares with 3700 AVHRR scenes used in this study. The paucity of data in the Barents Sea during the CZCS mission was due to its intermittent operation [Hooker et al., 1993]. Therefore blooms could have been obscured by cloud or simply not detected at all.

[15] The strong correlation between the TS pairing and AVHRR coccolithophore detection could be due to stable stratification within the water column which favours bloom development [Nanninga and Tyrrell, 1996]. The predicted freshening (from meltwater and increased precipitation) and warming of the sub-polar seas [Delworth and Dixon, 2000], possibly due to global climate change, could mean that there will be increased instances of coccolithophore blooms in the Barents Sea in the future This in turn could be linked to theories predicting a weakening of the thermohaline circulation [Dickson et al., 2002] in the north Atlantic. This is the manifestation of the biological system responding to weak climatic signals other than those that dominate the driving variables [Taylor et al., 2002]; no correlation was found between the North Atlantic Oscillation or ice extent and bloom occurrence.

[16] A major motivation for this study was to take advantage of the unique conspicuousness of $E$. huxleyi blooms to determine if they have been advancing into the Barents Sea as a consequence of climate change. The results are somewhat equivocal in this regard: blooms were detected before 1998 and so the recent blooms are clearly not a new phenomenon in the Barents Sea. However, the five-year continuous stretch of blooms (1999-2003) seems without precedent during the 20 years of AVHRR imagery that was analysed; the correlation with anomalously warm years also suggests the possibility of a link between global warming and increasing E. huxleyi activity in this area.

[17] Acknowledgments. This work was funded under NERC grant number NER/M/S/2003/00042. The AVHRR data were obtained from the NOAA Satellite Active Archive (SAA). We thank V. Ozhigin (PINRO, Murmansk) for the Kola transect data and P. Fossum, H. Gjøsæter, J. Herle and R. Pearce for the in situ sampling and analysis. We are indebted to Norman Kuring for first alerting us to these blooms in the Barents Sea.

\section{References}

Anseleme, B. (1998), Sea ice fields and atmospheric phenomena in Eurasiatic arctic seas as seen from the NOAA-12 satellite, Int. J. Remote Sens., 19, 307-316.
Bochkov, Y. A. (1982), Water temperature in the 0-200 m layer in the Kola Meridian Section in the Barents Sea, 1900-1981 (in Russian), Sb. Nauchn. Tr. PINRO, 46, 113-122.

Broerse, A. T. C., et al. (2003), The cause of bright waters in the Bering Sea in winter, Cont. Shelf Res., 23, 1579-1596.

Brown, C. W., and J. A. Yoder (1994), Coccolithophorid blooms in the global ocean, J. Geophys. Res., 99, 7467-7482.

Delworth, T. L., and K. W. Dixon (2000), Implications of the recent trend in the Arctic/North Atlantic Oscillation for the North Atlantic thermohaline circulation, J. Clim., 13, 3721-3727.

Dickson, B., et al. (2002), Rapid freshening of the deep North Atlantic Ocean over the past four decades, Nature, 416, 832-837.

Groom, S. B., and P. M. Holligan (1987), Remote sensing of coccolithophore blooms, Adv. Space Res., 7(2), 273-278.

Holligan, P. M., et al. (1993), A biogeochemical study of the coccolithophore Emiliania huxleyi in the North Atlantic, Global Biogeochem. Cycles, 7, 879-900.

Hooker, S. B., et al. (1993), Ocean color imaging: CZCS to SeaWiFS, Mar. Technol. Soc. J., 27, 3-15.

Iglesias-Rodriguez, M. D., et al. (2002), Representing key phytoplankton functional groups in ocean carbon cycle models: Coccolithophorids, Global Biogeochem. Cycles, 16(4), 1100, doi:10.1029/2001GB001454.

Kögeler, J., and F. Rey (1999), Ocean colour and the spatial and seasonal distribution of phytoplankton in the Barents Sea, Int. J. Remote Sens., 20, $1303-1318$

Merico, A., et al. (2003), Analysis of satellite imagery for Emiliania huxleyi blooms in the Bering Sea before 1997, Geophys. Res. Lett., 30(6), 1337, doi:10.1029/2002GL016648.

Nanninga, H. J., and T. Tyrrell (1996), Importance of light for the formation of algal blooms by Emiliana huxleyi, Mar. Ecol. Prog. Ser., 136, 195203.

Neckel, H., and D. Labs (1984), The solar radiation between 3300 and $12500 \AA$ A, Solar Phys., 90, 205-258.

Rao, C. R. N., and J. H. Chen (1995), Intersatellite calibration linkages for the visible and near-infrared channels of the advanced very high-resolution radiometer on the NOAA-7, NOAA-9, and NOAA-11 spacecraft, Int. J. Remote Sens., 16, 1931-1942.

Rao, C. R. N., and J. H. Chen (1996), Post-launch calibration of the visible and near-infrared channels of the advanced very high resolution radiometer on the NOAA-14 spacecraft, Int. J. Remote Sens., 17, $2743-2747$

Rossow, W. B., and R. A. Schiffer (1999), Advances in understanding clouds from ISCCP, Bull. Am. Meteorol. Soc., 80, 2261-2287.

Stumpf, R. P., and J. R. Pennock (1989), Calibration of a general optical equation for remote sensing of suspended sediments in a moderately turbid estuary, J. Geophys. Res., 94, 14,363-14,371.

Taylor, A. H., et al. (2002), Extraction of a weak climatic signal by an ecosystem, Nature, 416, 629-632.

Trees, C. C., et al. (1992), Bio-optical variability across the Arctic Front, Polar Biol., 12, 455-461.

T. J. Smyth, Plymouth Marine Laboratory, Prospect Place, Plymouth PL1 3DH, UK.(tjsm@pml.ac.uk)

T. Tyrrell, School of Ocean and Earth Science, Southampton Oceanography Centre, University of Southampton, Southampton SO14 3ZH, UK.

B. Tarrant, Department of Geography, University College London, London WC1H 0AP, UK. 